\title{
Effect of Rhus coriaria extract on wound healing potential in Sprague Dawley rats
}

\section{Abstract}

Background and objective: Rhus coriaria, a well-known spice grown in the Kurdistan region of Iraq, commonly known in the Middle East Region by (Sumac), is reported to enclose many medical benefits. This study assessed the effects of topical application of Rhus coriaria extract on the rate of wound closure, the Hydroxyproline (HXP) and Nitric Oxide (NO) levels were measured using the healed skin tissue homogenate the elemental composition of the plant was screened.

Methods: Adult male Sprague Dawley rats were topically treated with $0.2 \mathrm{~mL}$ of the vehicle (gum accacia), Intrasite gel (positive control), 100 and $200 \mathrm{mg} / \mathrm{kg}$ of Rhus coriaria extract.

Results: Wounds dressed with the extract and Intrasite gel healed significantly earlier than those with the vehicle. The high content of HXP and NO proves that the effect of Rhus coriaria extract on an excision wound model was significantly higher than that of the vehicle itself. The highest mineral contents were in Potassium, Calcium, Phosphorus, Magnesium and the extract was rich in energy content.

Conclusion: The current study concluded that Rhus coriaria showed high potential in wound healing activity.

Keywords: Rhus coriaria; Wound healing; Hydroxyproline; Nitric oxide.

\section{Introduction}

Rhus coriaria is a plant from family Anacardiaceae, commonly known as (Sumac) in the Mediterranean countries. It is a very popular spice, condiment and a major souring agent, ${ }^{1}$ which found to possess different pharmacological activities such as antimicrobial ${ }^{2}$ anti diabetic ${ }^{3}$ hepato -protective $^{4}$ hypo-glycaemic ${ }^{5}$ antioxidant, $^{6}$ DNA protective and antibacterial activities. ${ }^{8}$ Previous studies have reported that the extract of Rhus species may be a source of bioflavonoids that revealed the higher activity of this species. ${ }^{9}$ Also, Sumac is a rich source of hydrolysabletannins, ${ }^{6}$ Gallotannins. $^{10}$ Moreover, isomers of gallotannins and flavonoids were reported to be present in Rhus coriaria. ${ }^{11}$ The physicochemical properties along with the mineral constituents of sumac were reported $^{12}$ also potassium, calcium, magnesium and phosphorus were found to be predominant elements in Rhus coriaria fruit. This study aimed to assess potential effects of Rhus coriaria on the enhancement of wound healing process in rats.

\section{Methods}

\section{Plant Extraction:}

Dried fruit part Rhus coriaria was used. For the preparation of ethanol extract, 100 grams of their fine powder was soaked in 1000 milliliters of ethanol for three days. After that, the mixture was filtered by filter paper (Whatman No.1) and extracted under compact pressure in a rotating evaporator.

\section{Elemental composition:}

$500 \mathrm{gm}$ of the fine powder of Rhus coriaria was sent to the Consolidated Laboratory (M) Sdn. Bhd. Kuala Lumpur, Malaysia for the analysis of the minerals, fats and elemental compositions.

* Department of Pharmacognosy, College of Pharmacy, Hawler Medical University, Erbil, I raq. 


\section{In vivo wound healing:}

Rhus coriaria ethanol extract was dissolved by using the vehicle: gum acacia (a complex mixture of polysaccharides and glycoproteins) that was used after dissolving in normal saline as described by Zahra et al. ${ }^{13}$ Two grams of gum acacia was dissolved in $100 \mathrm{ml}$ of normal saline. From this, $10 \mathrm{ml}$ of solution, which contains $200 \mathrm{mg}$ of gum acacia, was used for dissolving one gram and two grams of Rhus coriaria ethanol extract. Intrasite gel: an amorphous gel, containing $2.3 \%$ of modified carboxymethyl cellulose (CMC) polymer with propylene glycol $(20 \%)$ was used as the reference control. Sprague dawley adult male rats were randomly divided into four groups of 6 rats each. Each rat that weighed between 185-200 g were housed separately (one rat per cage). The animals were maintained on a standard pellet diet and tap water. The animals were anesthetized with a light dosage of ketamin and xylazine anesthesia. The skin was shaved by electrical shaver, disinfected with $70 \%$ alcohol. An area of uniform wound $2.00 \mathrm{~cm}$ in diameter was excised from the nape of the dorsal neck of all rats with the aid of round seal as described by Rawat et al. ${ }^{14}$ Topical application of $0.2 \mathrm{ml}$ of the vehicle (Gum acacia) was applied topically to the wounds of Group 1 rats twice a day. Group 2 rats were topically applied twice daily with $0.2 \mathrm{ml}$ of $100 \mathrm{mg} / \mathrm{kg}$ of Rhus coriaria ethanol extract, and the Group 3 rats were dressed twice daily with $0.2 \mathrm{ml}$ of $200 \mathrm{mg} /$ kg Rhus coriaria ethanol extract. Group 4 rats were dressed twice daily with $0.2 \mathrm{ml}$ of $200 \mathrm{mg} / \mathrm{kg}$ reference drug (Intrasite gel). The contraction of the wound area was measured. Wound areas were traced manually and calculated in square millimeters. The wound closure area of each animal was assessed by tracing the wound on days 0,7 and 14 post-wounding surgery. The wound closure rate was expressed as the percentage of wound area compared with that on the post-operative day by using transparency paper and a permanent marker under general anesthesia (a mixture of Ketamine and Xylazil) as described by Abdulla et al. ${ }^{15}$ The wound areas recorded were measured by using a graph paper. The percent wounds healing on these days were determined. The number of days required for falling of scar without any residual raw wound gave the period of epithelization. The wound area was measured immediately by placing a transparent tracing paper over the wound and tracing it out. The tracing paper was placed on $1 \mathrm{~mm}^{2}$ graph sheet and traced out. The squares were counted and the area recorded.

Determination of Hydroxyproline and Nitric Oxide:

The wound tissue homogenate from each rat was prepared at $4^{\circ} \mathrm{C}$ by using a teflon homogenizer (Polytron, Germany). After centrifugation at $4,500 \mathrm{rpm}$ for $15 \mathrm{~min}$ at $4^{\circ} \mathrm{C}$, the supernatant was used for Nitric oxide (NO) and hyroxyproline (HXP) determinations using the NO and HXP assay kit (Cayman Chemical Co., USA).

\section{Statistical analysis:}

All values are expressed as mean \pm S.E.M. and the statistical significance of differences among groups was assessed using Post Hoc test, one-way ANOVA. A value of $P<0.05$ was considered significant.

\section{Results}

\section{Elemental composition}

The chemical analysis of Rhus coriaria fruit part is shown in Table 1. The highest mineral contents were Potassium (544.3 mg/100g), Calcium (342.98 $\mathrm{mg} / 100 \mathrm{~g}$ ), Phosphorus (109.88 mg/100g) and Magnesium $(88.75 \mathrm{mg} / 100 \mathrm{~g})$, while it was rich in energy content $(441 \mathrm{kcal} / 100 \mathrm{~g})$. 


\section{In vivo wound healing test}

The excision model was used, in which grossly wounds dressed with Rhus coriaria or with intrasite gel showed considerable signs of dermal healing and significantly healed faster compared to group received the vehicle (gum acacia). Table 2 shows the effects of Rhus coriaria ethanol extract on the percentage of wound healed on days post-surgery.

Table 1: Elemental composition of Rhus coriaria fruit part.

\begin{tabular}{lcc}
\hline Test parameter & Rhus coriaria & Unit \\
\hline Energy & 441 & $\mathrm{kcal} / 100 \mathrm{~g}$ \\
Total fat & 18.1 & $\mathrm{~g} / 100 \mathrm{~g}$ \\
Carbohydrate & 65.3 & $\mathrm{~g} / 100 \mathrm{~g}$ \\
Protein & 4.2 & $\mathrm{~g} / 100 \mathrm{~g}$ \\
Cholesterol & $<0.001$ & $\mathrm{mg} / 100 \mathrm{~g}$ \\
Dietary fibre & 0.6 & $\mathrm{~g} / 100 \mathrm{~g}$ \\
Monosaturated fat & 7.37 & $\mathrm{~g} / 100 \mathrm{~g}$ \\
Polysaturated fat & 4.29 & $\mathrm{~g} / 100 \mathrm{~g}$ \\
Saturated fat & 6.4 & $\mathrm{~g} / 100 \mathrm{~g}$ \\
Trans fat & $<0.01$ & $\mathrm{~g} / 100 \mathrm{~g}$ \\
Phosphorus $(\mathrm{P})$ & 109.88 & $\mathrm{mg} / 100 \mathrm{~g}$ \\
Potassium $(\mathrm{K})$ & 544.3 & $\mathrm{mg} / 100 \mathrm{~g}$ \\
Sodium $(\mathrm{Na})$ & 3.65 & $\mathrm{mg} / 100 \mathrm{~g}$ \\
Zinc $(\mathrm{Zn})$ & 1.07 & $\mathrm{mg} / 100 \mathrm{~g}$ \\
Calcium (Ca) & 342.98 & $\mathrm{mg} / 100 \mathrm{~g}$ \\
Copper (Cu) & 0.55 & $\mathrm{mg} / 100 \mathrm{~g}$ \\
Iron (Fe) & 2.92 & $\mathrm{mg} / 100 \mathrm{~g}$ \\
Magnesium (Mg) & 88.75 & $\mathrm{mg} / 100 \mathrm{~g}$ \\
Manganese (Mn) & 1.04 & $\mathrm{mg} / 100 \mathrm{~g}$ \\
Selenium (Se) & $<0.002$ & $\mathrm{mg} / 100 \mathrm{~g}$ \\
\hline
\end{tabular}

Table 2: Effect of Rhus coriaria ethanol extract on percentage wound healing in the experimental rats.

\begin{tabular}{llcc} 
Animal groups & Treatments & Day 7 & surgery \\
& & $19^{\mathrm{a}}$ & Day 14 \\
\hline group 1 & $0.2 \mathrm{ml} / \mathrm{kg}$ Gum accacia & $59.67^{\mathrm{b}}$ & $22^{\mathrm{a}}$ \\
group 2 & $100 \mathrm{mg} / \mathrm{kg}$ Rhus coriaria & $61^{\mathrm{b}}$ & $66.8^{\mathrm{b}}$ \\
group 3 & $200 \mathrm{mg} / \mathrm{kg}$ Rhus coriaria & $68.67^{\mathrm{b}}$ & $90^{\mathrm{c}}$ \\
group 4 & $0.2 \mathrm{ml} / \mathrm{kg}$ Intrasite gel & $86.4^{\mathrm{b}}$ \\
\hline
\end{tabular}


The percentage of healing in the vehicle control group wounds was significantly lower than those of Rhus coriaria extract treated groups and intrasite gel wounds at $P<0.05$ (Figure 1). On day 14 post-surgery showed that wound dressed with Rhus coriaria extract showed comparatively less scar width at wound closure compared to the vehicle-treated group. Data expressed as Mean \pm SEM, Mean values $(\mathrm{n}=6)$ followed by different letters ( $a, b$, and c) in a column are significantly different as compared to Gum acacia group $(P \leq 0.05)$.

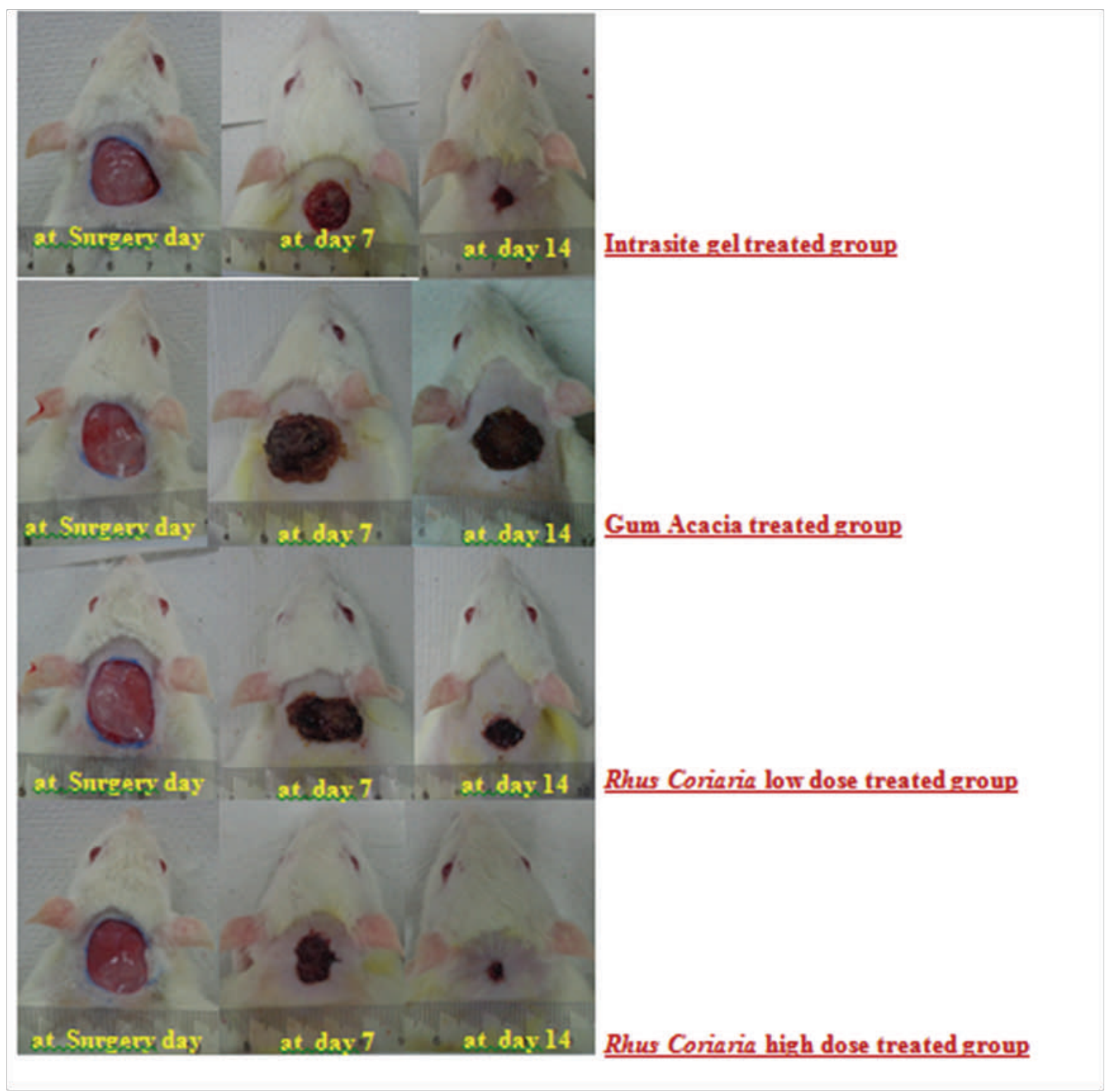

Figure 1: Gross appearance of wound healing on different days post-surgery. First row/ Rats treated with intrasite gel shows remarkably smaller wound closure area compared to vehicle. Second row/ Rats treated with $0.2 \mathrm{ml}$ Gum acacia shows wide wound closure area. Third row/Rats treated with $(100 \mathrm{mg} / \mathrm{kg})$ of Rhus coriaria shows remarkably moderate wound closure area compared to vehicle. Fourth row/Rats treated with $(200 \mathrm{mg} / \mathrm{kg})$ of Rhus coriaria shows remarkably smaller wound closure area compared to vehicle. 
Treatment with Rhus coriaria ethanol extract significantly increased the hydroxyproline and nitric oxide levels as compared to the vehicle group as shown in Figure 2 and Figure 3.

\section{Discussion}

The wound healing achievement of Rhus coriaria may be due to the antioxidant content and the elevated free radical scavenging activity. The free radicals and reactive oxygen species made during tissue injury are theoretically concerned in late wound curing. ${ }^{15-17}$ From the results, it is obvious that the treatment with the reference control (intrasite gel) significantly increased the collagen content represented as high level of hydroxylproline in comparison to the decreased levels of the vehicle control group (gum acaccia). Moreover, this study showed that Rhus coriaria was able to accelerate the wound healing process in vivo in doses of $100 \mathrm{mg} / \mathrm{kg}$ and $200 \mathrm{mg} / \mathrm{kg}$ based on the gross findings. Also, the high content of hydroxyproline and nitric oxide proves that the effect of Rhus coriaria extract on an excision wound model was significantly higher than that of the vehicle itself. These results were in agreement with the previous studies published elsewhere. ${ }^{16,18}$ A previous study has shown that healing can be accelerated and enhanced by the use of specific wound dressing or care

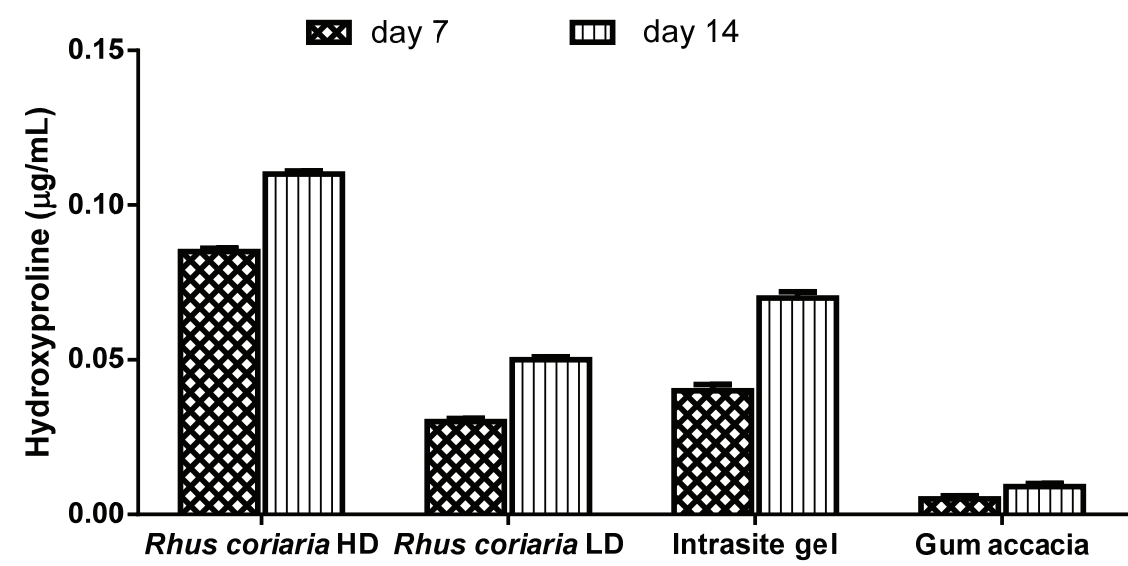

Figure 2: Hydroxyproline (HXP) levels in healed skin homogenates treated with $2 \%$ gum accacia, Intrasite gel, Rhus coriaria LD(100 mg/kg), Rhus coriaria HD (200 mg/kg) $P \leq 0.05$.

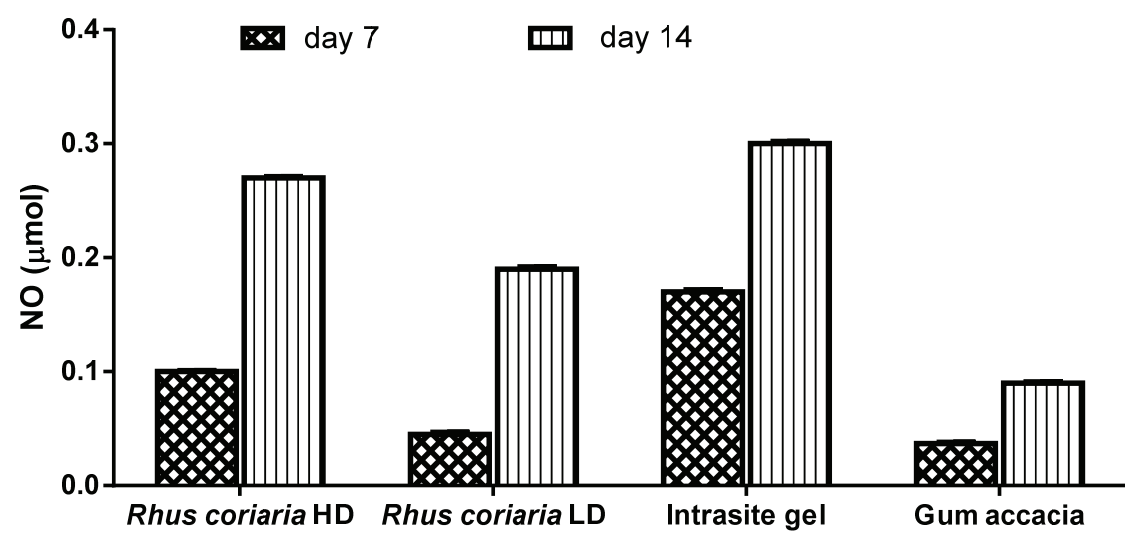

Figure 3: Nitric oxide (NO) levels in healed skin homogenates treated with $2 \%$ gum accacia, Intrasite gel, Rhus coriaria LD (100 mg/kg), Rhus coriaria HD (200 mg/kg) $\mathrm{P} \leq 0.05$. 
product and techniques and that it is not a passive process. ${ }^{19}$ It has been observed that plant constituents can significantly accelerate the healing process and improve the quality of wound healing. ${ }^{18}$ Numerous studies have shown that plant compounds could potentially be therapeutic agents to treat wounds. ${ }^{17,18,20,21}$ The findings of this study are also in line with previous studies reported by various authors. $^{15,17}$

\section{Conclusion}

Topical application of Rhus coriaria has an enhancing effect on the wound healing process through stimulating hydroxyproline production and scavenging NO. Therefore, Rhus coriaria is considered potentially useful in accelerating wounds, but additional research is needed to show the exact mechanisms of it.

\section{Competing interests}

The author declares that she has no competing interests.

\section{References}

1. Shabbir A. Rhus coriaria linn, a plant of medicinal, nutritional and industrial importance: a review. J Anim Plant Sci 2012; 22(2):505-12.

2. Nasar-Abbas S, Halkman AK. Antimicrobial effect of water extract of sumac (Rhus coriaria L.) on the growth of some food borne bacteria including pathogens. Int J Food Microbiol 2004; 97(1):63-9.

3. Mohammadi S, Kouhsari SM, Feshani AM. Antidiabetic properties of the ethanolic extract of Rhus coriaria fruits in rats. Daru: Journal of Faculty of Pharmacy, Tehran University of Medical Sciences 2010;18(4):270.

4. Pourahmad J, Eskandari MR, Shakibaei R, Kamalinejad M. A search for hepatoprotective activity of aqueous extract of Rhus coriaria L. against oxidative stress cytotoxicity. Food and chemical toxicology 2010; 48(3):854-8.

5. Giancarlo S, Rosa LM, Nadjafi F, Francesco M. Hypoglycaemic activity of two spices extracts: Rhus coriaria L. and Bunium persicum Boiss. Natural product research 2006; 20(9):882-6.

6. Kosar M, Bozan B, Temelli F, Baser K. Antioxidant activity and phenolic composition of sumac (Rhus coriaria L.) extracts. Food chemistry 2007; 103 (3):952-9.

7. Chakraborty A, Ferk F, Simić T, Brantner A, Dušinská $M$, Kundi $M$, et al. DNA-protective effects of sumach (Rhus coriaria L.), a common spice: results of human and animal studies.
Mutation Research/Fundamental and Molecular Mechanisms of Mutagenesis 2009; 661(1):10-7.

8. Sokmen A, Jones BM, Erturk M. The in vitro antibacterial activity of Turkish medicinal plants. Journal of Ethnopharmacology 1999; 67(1):79-86.

9. Svenningsen $A B$, Madsen $K D$, Liljefors $T$, Stafford GI, van Staden J, Jäger AK. Biflavones from Rhus species with affinity for the GABA A/benzodiazepine receptor. Journal of Ethnopharmacology 2006; 103(2):276-80.

10. Zalacain A, Prodanov M, Carmona M, Alonso G. Optimisation of extraction and identification of gallotannins from sumac leaves. Biosystems Engineering 2003; 84(2):211-6.

11. Regazzoni L, Arlandini E, Garzon D, Santagati NA, Beretta G, Facino RM. A rapid profiling of gallotannins and flavonoids of the aqueous extract of Rhus coriaria L. by flow injection analysis with high-resolution mass spectrometry assisted with database searching. Journal of pharmaceutical and biomedical analysis 2013; 72:202-7.

12. Özcan M, Haciseferogullari H. A condiment [sumac (Rhus coriaria L.) fruits]: some physicochemical properties. Bulgarian Journal of Plant Physiology 2004; 30(3-4):74-84.

13. Zahra A, FAK A, Mahmood A, Al hadi A, Suzy S, Sabri S, Latif I and Ketuly K. Acute toxicity study and wound healing potential of Gynura procumbens leaf extract in rats. Journal of Medicinal Plants Research 2011; 5(12):2551-8.

14. Rawat S, Singh R, Thakur P, Kaur S, Semwal A. Wound healing Agents from Medicinal Plants: A Review. Asian Pacific Journal of Tropical Biomedicine 2012; 2(3):S1910-S7.

15. Abdulla MA, Fard AA, Sabaratnam V, Wong K-H, Kuppusamy UR, Abdullah $\mathrm{N}$, et al. Potential activity of aqueous extract of culinary-medicinal Lion's Mane mushroom, Hericium erinaceus (Bull.: Fr.) Pers. (Aphyllophoromycetideae) in accelerating wound healing in rats. Int $\mathrm{J}$ Med Mushrooms 2011; 13(1)::33-9

16. Cheng P-G, Phan C-W, Sabaratnam V, Abdullah N, Abdulla MA, Kuppusamy UR. Polysaccharides-Rich Extract of Ganoderma lucidum (MA Curtis: Fr.) P. Karst Accelerates Wound Healing in Streptozotocin-Induced Diabetic Rats. Evidence-Based Complementary and Alternative Medicine 2013; 2013.

17. Hajiaghaalipour F, Kanthimathi M, Abdulla MA, Sanusi J. The effect of Camellia sinensis on wound healing potential in an animal model. Evidence-Based Complementary and Alternative Medicine 2013; 2013.

18. Al-Bayaty FH, Abdulla MA, Hassan MIA, Ali HM. Effect of Andrographis paniculata leaf extract on wound healing in rats. Natural product research 2012; 26(5):423-9.

19. Cooper D. Optimizing wound healing. A practice within nursing's domain. The Nursing clinics of North America 1990; 25(1):165. 
20. Akkol EK, Koca U, Peşin I, Yılmazer D, Toker G, Yeşilada E. Exploring the wound healing activity of Arnebia densiflora(Nordm.) Ledeb. by in vivo models. Journal of ethnopharmacology 2009; 124 (1):137-41.

21. Csupor D, Blazsó G, Balogh Á, Hohmann J. The traditional Hungarian medicinal plant Centaurea sadleriana Janka accelerates wound healing in rats. Journal of ethnopharmacology 2010; 127(1):193-5. 